\title{
Erratum to: 'Pre-endoscopy point of care test (Simtomax- IgA/lgG-Deamidated Gliadin Peptide) for coeliac disease in iron deficiency anaemia: diagnostic accuracy and a cost saving economic model'
}

Michelle Shui Yee Lau", Peter D. Mooney ${ }^{1}$, William L. White', Victoria Appleby², Sulleman Moreea², Ismail Haythem ${ }^{3}$, Joshua E. Elias ${ }^{4}$, Kiran Bundhoo ${ }^{4}$, Gareth D. Corbett ${ }^{4}$, Liam Wong ${ }^{5}$, Her Hsin Tsai ${ }^{5}$, Simon S. Cross ${ }^{6}$, John M. Hebden ${ }^{7}$, Sami Hoque ${ }^{3}$ and David S. Sanders ${ }^{1}$

\section{Erratum}

Unfortunately, after publication of this article [1] it was noticed that several authors were missing their middle initials. The corrected author list can be seen above and the original article has been updated to reflect this change.

\footnotetext{
Author details

'Academic Department of Gastroenterology, Royal Hallamshire Hospital, Sheffield Teaching Hospitals, Sheffield, UK. ²Department of Gastroenterology, Bradford Royal Infirmary, Bradford, UK. ${ }^{3}$ Department of Gastroenterology, Whipps Cross University Hospital, London, UK. ${ }^{4}$ Department of Gastroenterology, Addenbrooke's Hospital, Cambridge, UK. ${ }^{5}$ Department of Gastroenterology, Hull Royal Infirmary, Hull, UK. ${ }^{6}$ Academic Unit of Pathology, Department of Neuroscience, Faculty of Medicine, Dentistry \& Health, The University of Sheffield, Sheffield, UK. ${ }^{7}$ Department of Gastroenterology, Northern General Hospital, Sheffield Teaching Hospitals, Sheffield, UK.
}

Received: 28 September 2016 Accepted: 29 September 2016 Published online: 05 October 2016

\section{Reference}

1. Lau MSY, Mooney PD, White WL, Appleby V, Moreea S, Haythem I, Elias JE, Bundhoo K, Corbett GD, Wong L, Tsai HH, Cross SS, Hebden JM, Hoque S, Sanders DS. 'Pre-endoscopy point of care test (Simtomax- IgA/lgG-Deamidated Gliadin Peptide) for coeliac disease in iron deficiency anaemia: diagnostic accuracy and a cost saving economic model'. BMC Gastroenterol. 2016;16:115. doi:10.1186/s12876-016-0521-5.

\footnotetext{
*Correspondence: michellelau@doctors.org.uk

${ }^{1}$ Academic Department of Gastroenterology, Royal Hallamshire Hospital,

Sheffield Teaching Hospitals, Sheffield, UK

Full list of author information is available at the end of the article
} 